DOI 10.37882/2223-2982.2021.09.09

\title{
ОСОБЕННОСТИ РАЗРАБОТКИ И РЕАЛИЗАЦИИ МОДЕЛИ ПЕДАГОГИЧЕСКОГО ОБЕСПЕЧЕНИЯ ИНТЕГРАЦИИ ДОШКОЛЬНОГО И ДОПОЛНИТЕЛЬНОГО ОБРАЗОВАНИЯ В ГОРОДСКОЙ ОБРАЗОВАТЕЛЬНОЙ СРЕДЕ
}

\section{FEATURES OF THE DEVELOPMENT AND IMPLEMENTATION OF THE MODEL OF PEDAGOGICAL SUPPORT FOR THE INTEGRATION OF PRESCHOOL AND ADDITIONAL EDUCATION IN THE URBAN EDUCATIONAL ENVIRONMENT}

\section{Ereshkina}

Summary: The paper considers the structural components of the author's model of pedagogical support for the integration of preschool and additional education in the urban educational environment. Its tasks, principles, approaches, features, and forms are described. Special attention is paid to pedagogical technologies in the formation of social adaptation and the development of the motivational-need sphere of preschool children.

Keywords: integration of preschool and additional education, model of pedagogical support, social adaptation, motivational and need sphere of preschool children.

\section{Введение}

Д ополнительное образование детей - обязательный компонент полноценного общего образования, сочетающий в себе воспитание, обучение итие личности ребенка. В настоящее время дополнительное образование детей социально востребовано и органично вписано в единое образовательное пространство. Дополнительное образование благоприятствует развитию детей, оно интересно для самого ребенка и решает ряд проблем разностороннего развития дошкольника. На данный момент в России активно протекает процесс внедрения региональных систем интеграции дошкольного образования с другими системами. Вместе с тем, задача совершенствования педагогического обеспечения дошкольного и дополнительного образования в городской образовательной среде сохраняет свою актуальность.

В этой связи, педагоги и руководители дошкольных образовательных организаций (далее ДОО) ищут пути решения проблем предоставления дополнительных об-
Ерешкина Лариса Владимировна

аспирант, ФГБОУ ВО «СГУ имени Н.Г. Чернышевского»,

2. Саратов

larisa-700@mail.ru

Аннотация: В работе рассматриваются структурные компоненты разработанной автором модели педагогического обеспечения интеграции дошкольного и дополнительного образования в городской образовательной среде. Описываются задачи педагогического обеспечения, принципы, подходы, особенности, формы. Особое внимание уделено педагогическим технологиям в формировании социальной адаптации и развитии мотивационно-потребностной сферы дошкольников.

Ключевые слова: интеграция дошкольного и дополнительного образования, модель педагогического обеспечения, социальная адаптация, мотивационно-потребностная сфера дошкольников.

разовательных услуг в соответствии с современными требованиями, с учетом современных тенденций дошкольного образования, социального заказа и развития ребёнка-дошкольника [1].

Педагогическое обеспечение при этом представляется важным компонентом интеграции дошкольного и дополнительного образования, так как при его отсутствии интеграция в условиях городской образовательной среды происходит стихийно и зависит от внешнего управления, требуя привлечения большого количества ресурсов.

Под педагогическим обеспечением мы понимаем, прежде всего, целенаправленное, высокоорганизованное, эффективное взаимодействие участников образовательных отношений, основанное на принципах диалогичности, компромисса, приоритетного выбора взаимоприемлемых решений, что, стоит сказать, в значительной степени сокращает возможность возникновения конфликтогенных факторов (катализаторов конфликта) и способствует поддержанию здорового со- 
циально-психологического климата в образовательной организации, а также формированию смысловой определенности профессионально-личностных целей, задач, содержательного наполнения деятельности и др. [2].

Существующие модели интеграции, которые были рассмотрены нами в ранее опубликованных материалах [3], призваны информационно и методически сориентировать ДОО в части организации взаимодействия дошкольного и дополнительного образования, предоставить пошаговый алгоритм функционирования и мониторинга выбранных моделей.

Рассматривая дошкольное и дополнительное образование, особого внимания заслуживает вопрос социальной адаптации, которая является условием «социализации» детей. Социализация - процесс и результат усвоения ребёнком социального опыта. В результате социализации ребенок становится культурным, образованным и воспитанным взрослым человеком. А результатом социализации детей дошкольного возраста является готовность ребенка к школе.

Рассматривая старший дошкольный возраст, необходимо отметить, что он является наиболее важным относительно готовности к школе, следовательно, педагогу надо обеспечить успешное вхождение дошкольника в образовательную среду [4]. Для этого работа педагога должна выстраиваться по 3 векторам: мотивационная готовность, эмоционально-волевая готовность, интеллектуальная готовность.

На важность мотивационной готовности указывали Ш.А. Амонашвили, Л.В. Артемова, Р.С. Буре, А.М. Прихожан, Н.Н. Толстых и др. Обучение в условиях современного социума предъявляет высокие требования к эмоционально-волевой готовности будущего школьника, которая играет огромную роль в усвоении знаний, умений и навыков, в установлении контактов с окружающими. На важность данной сферы для социальной адаптации дошкольника указывали Л.С. Выготский, Л.И. Божович, М.М. Гуткина и др. Одной из главных предпосылок, которая помогает старшему дошкольнику успешно учиться, является интеллектуальная готовность, предполагающая формирование у ребенка начальных умений в области учебной деятельности. Указанные компоненты находят эффективное развитие в рамках следующих подходов: субъектно-ориентированный, социокультурный, интегративно-вариативный [5].

На основании вышесказанного, мы считаем, что в условиях города необходимо сосредоточить внимание на таких подходах как: субъектно-ориентированный, социокультурный, интегративно-вариативный.

Актуальность субъектно-ориентированного подхода обусловлена насыщенными условиями жизни в городе, которые требуют от педагогов дополнительного образования большего внимания к развитию субъектности и самостоятельности дошкольника.

В аспекте социокультурного подхода обеспечение качества дополнительных общеразвивающих программ для дошкольников зависит от того, в какой мере учитываются территориальные и культурные особенности города. У многих городов имеются свои традиции, памятники, ресурсы, ценностные ориентиры, охраняемые горожанами, являющиеся значимыми для разных поколений города, поэтому историческое наследие должно учитываться при разработке дополнительных общеразвивающих программ, находить отражение в содержании и формах дополнительного образования.

Внедрение интегративно-вариативного подхода предполагает идея интеграции дошкольного и дополнительного образования в ДОО: от создания вариантов и способов получения дополнительного образования посредством интеграции элементов внутренней и внешней среды образовательной организации до готовности детей (или их родителей) к осознанному выбору дополнительной общеразвивающей программы.

Таким образом, интеграция дополнительного и дошкольного образования является актуальной проблемой, так как она позволяет решить детям (в том числе детям с ограниченными возможностями здоровья, с особыми образовательными потребностями, с признаками одаренности и т.п.) успешно адаптироваться в современном обществе, удовлетворить индивидуальные потребности, развить свой творческий потенциал. Выявлено, что эффективная интеграция в условиях городской образовательной среды возможна посредством педагогического обеспечения.

Целью данной работы является разработка и реализация модели педагогического обеспечения интеграции дошкольного и дополнительного образования в городской образовательной среде (далее Модель).

\section{Материалы и методы}

С целью сбора материалов для разработки Модели было осуществлено предварительное диагностическое исследование социальной адаптации. Для проверки действия Модели диагностика также была выполнена после внедрения Модели. Этап диагностирования включал в себя тестирование детей старшего дошкольного возраста МАДОУ «ЦРР - детский сад № 215 «Капельки солнца», МАДОУ «Детский сад №2», МДОУ «Центр развития ребенка - детский сад №247», МДОУ «Центр развития ребёнка - детский сад №13». Всего в исследовании приняли 258 детей. Целью диагностики явилось выявление 
особенностей социальной адаптации детей старшего дошкольного возраста.

В работе с дошкольниками использовались следующие методики: методика «Игровая комната» (О.М. Дьяченко); моделирование проблемной ситуации; методика вербального выбора «День рождения» (М. Панфилова), модификация социометрического метода Дж. Морено для детей (Я.Л. Коломинского), методика выявления уровня развития произвольности (анализ результатов, предложенный Н.И. Гуткиной), методика мотивационных предпочтений «Три желания» (А.М. Прихожан, Н.Н. Толстых), методика выявления познавательной активности (по В.С. Юркевичу).

При изучении социализации детей дошкольного возраста были исследованы следующие компоненты готовности к школе: мотивационный, эмоционально-волевой, интеллектуальный.

В ходе выполнения исследования были реализованы наиболее актуальные педагогические технологии, которые обеспечивают доступность и эффективность интеграции дошкольного и дополнительного образования городских дошкольников:

- Проектирование индивидуальной образовательной деятельности (далее ИОД). Ее результатом является программа, план, маршрут ИОД. Дает возможность организовать проектирование ИОД каждого дошкольника в групповой деятельности. Эффективность обеспечивается тем, что учитываются индивидуальные интересы и потребности, личностные характеристики дошкольника. Особенно важна в городских ДОО, где много дошкольников, у каждого есть свои интересы и потребности, которые важно учесть в процессе обучения и воспитания [6].

- Технология проектной деятельности. Ребенок может включиться как в индивидуальный проект, так и в групповой, выбрать тему и проблему по возможностям и интересам. Технология приучает дошкольников не столько использовать имеющийся ресурс, сколько создавать свой [7].

- «Портфолио». Позволяет дошкольнику представить собрание своих работ, которые демонстрируют его усилия, прогресс и достижения в определенной области знаний; осмысливать выполненную деятельность, систематизировать накапливаемый опыт, знания, определить направления развития, облегчить помощь или консультирование со стороны педагогов или специалистов в данной сфере, осуществить объективную оценку успехов [8].

- Погружение. Предполагает комплексное изучение темы, которая объединяет различные образовательные области и использует ресурсы до- полнительного образования дошкольников как в свободное время, так и во время образовательной деятельности. Дает возможность организовать разностороннюю деятельность всего коллектива, каждому выбрать содержание и форму участия в образовательной деятельности, иными словами, у каждого дошкольника есть индивидуальный, свой маршрут обучения.

- Творческие мастерские. Создана А. Валлоном, П. Ланжевеном, Ж. Пиаже. Предполагает обучение подрастающего поколения способам получения знаний и умений. Суть данной технологии заключается в самостоятельном «открытии» информации посредством исследования ее связи с практикой. Творческие мастерские по различным видам деятельности эффективны в различных структурах, где есть (приглашается) профессионал своего дела [9].

- Дистанционные технологии обучения по дополнительным образовательным программам. Позволяет дошкольникам заниматься по месту жительства в удобное время и в необходимом индивидуальном темпе. Именно такие технологии позволяют эффективно организовать интегрированное обучение средствами использования виртуальных экскурсий, использования видеоматериалов, музыкальных клипов, коллекции рисунков и т.п. [10].

\section{Результаты и обсужАение}

Разработана модель педагогического обеспечения интеграции дошкольного и дополнительного образования в городской образовательной среде. Модель решает следующие задачи:

- активизация институциональных и личностных ресурсов;

- формирование мотивации, потребностей социальной адаптации дошкольников;

- овладение социальными ценностями;

- становление социальных чувств, эмоциональных переживаний;

- формирование волевых проявлений дошкольников.

Разработанная Модель базируется на следующих принципах:

1. Принцип нацеленности на эффективный образовательный результат. Указывает на ориентацию субъектов интеграции на повышение качества образования в целом.

2. Принцип создания здоровой духовно-нравственной среды. Способствует созданию здоровой духовно-нравственной среды в ДОО и структурах дополнительного образования, в целом. 
3. Принцип регулирования взаимодействия детей старшего дошкольного возраста. Способствует обогащению и расширению социального опыта детей дошкольного возраста, развитию коммуникативных умений и навыков, воспитанию у дошкольников внимательного отношения к людям и подобное.

4. Принцип развития и обогащения социальных связей городских детей. Позволит повысить качество дополнительного образования, расширяя сферу социального взаимодействия дошкольников, обеспечивая тем самым их адаптацию, и социальную устойчивость.

5. Принцип социального партнерства и сотрудничества. Обусловлен особенностями городской среды, в которой невозможно обеспечить качество дополнительного образования дошкольников без взаимодействия и сотрудничества ДОО с социальными партнерами.

Результаты исследования по методике Керна-Йирасека показали, что у дошкольников готовность к обучению практически в $51 \%$ случаев находилась на низком уровне и 46\% - на среднем уровне. После формирующей работы и использования разработанной Модели показатели среднего и высокого уровня улучшились на 16\%.

Результаты проективной методики «Игровая комната» показали, что большая часть детей 52\% (132 чел.) проявляли инициативу в игровой деятельности и общительность. Проявили преимущественно среднюю активность в игровой деятельности, занимали подчинительную позицию в общении, т.е. среднее положение в структуре групповых взаимоотношений 35\% (86 детей). В игровом взаимодействии не активны, занимают подчинительную позицию в общении 40 детей или 13\%. Благодаря внедрению Модели игровая активность повысилась на 26\%, ребята стал более общительны, улучшились показатели в структуре групповых взаимоотношений на 17\%.

По характеристике «Благополучие общения» трудности в общении при первоначальной диагностике были выявлены у 68 дошкольников или 27\%; благополучные отношения и относительно благополучные отношения складываются у 73\% (190 детей). После внедрения Модели было выявлено снижение показателей трудностей в общении на $18 \%$ и повышение показателей благополучности отношений на $11 \%$.

По характеристике «Развитие игровых навыков»: 33\% (84 ребенка) показали высокий уровень сформированности игровых навыков. Средний уровень сформированности игровых навыков выявлен у 67\% (174 ребенка). Дети, показавшие низкий уровень развития игровых навыков, отсутствуют. После внедрения Модели было отмечено увеличение показателей высокого и среднего уровней на $15 \%$ и $26 \%$ соответственно.

По характеристике «Способы разрешения конфликтной ситуации» основная группа детей 79\% (204 ребенка) используют конструктивные методы выхода из конфликтной ситуации. Деструктивный метод выхода из игры, уход из ситуации свойственен 20\% детей (54 человек). После проведения формирующей работы конструктивные методы при выходе из конфликтных ситуаций стало использовать на $21 \%$ детей больше.

Проанализировав полученные результаты методики Дж. Морено в модификации Я.Л. Коломинского, выявлено, что среди дошкольников 4 отобранных ДОО 24 человека (9\%) относятся к категории «Звезды», к «Предпочитаемым» - 72 человека (28\%) из исследуемых, к «Принятым» - 108 человек (42\%) из группы и 54 детей (21\%) - к категории «Отверженные». Благодаря внедрению Модели детей, которые раньше были отнесены к группе «отверженные», стали охотнее принимать в игры, чаще общаться, уступать им игрушки. В целом, из категории «Отверженные» 24 детей перешли в группу «Принятые», из которой, в свою очередь, 54 детей перешли в группу «Предпочитаемые».

Методика выявления уровня развития произвольности «Да и Нет» среди 258 испытуемых выявила показатели высокого уровня у 70 детей $(27 \%)$, среднего у 25 детей (10\%) и низкого - у 163 детей (63\%). По результатам формирующей работы было выявлено повышение показателей высокого уровня на 18\% (44 детей) и снижение показателей низкого уровня на 34\% (68 детей). Было замечено, что у многих детей данная «игра» уже не вызывала значительные затруднения.

Полученные данные в ходе проведения методики «Три желания» показали доминирование желания личной направленности (73\% всех ответов). Адресованные другим людям, желания высказывались дошкольниками значительно реже (15.8\%), так же, как и желания «общечеловеческие» (11.2\%). Устойчивое преимущество в мотивационной сфере старших дошкольников имеет семья ребенка (63.4\%). Показатели после формирующей работы были значительно повышены по показателю «общечеловеческие желания» на 17\%, уже большее количество детей (на 17\%) отметили преобладание семьи в мотивационной сфере.

\section{Выво $\Delta ы$}

Полученные результаты подтверждают, что у большей половины старших дошкольников показатели готовности к социальной адаптации значительно улучшились после внедрения Модели. Наряду с четко выраженным игровым мотивом стали более отчетливыми учебный, социально-оценочный мотивы, а также внутренний. 
Предложенные нами педагогические технологии, формы, средства наиболее актуальны для дошкольников и педагогов основного дошкольного и дополнительного образования, а также соответствуют педагогическим условиям городских дошкольных образовательных организаций, что и было доказано результатами экспериментальной работы.

Особенности реализации Модели:

1. Обеспечение доступности дополнительного образования на основе педагогического обеспечения интеграции дошкольного и дополнительного образования, ресурсов ДОО и социума;

2. Интеграция обеспечивает эффективность и доступность дополнительного образования детей, проживающих в городской среде;

3. Дополнительное образование имеет преимущество в значительном расширении спектра видов детской деятельности, что способствует форми- рованию целостной личности, даже несмотря на фрагментарность поступающей информации;

4. Городская, социокультурная среда является важным ресурсом повышения эффективности педагогического обеспечения интеграции дошкольного и дополнительного образования в ДОО в условиях городской среды;

5. Комплекс предложенных подходов и принципов, педагогических технологий образования отражают современные тенденции развития общего образования и учитывают современные социально-экономические условия города, городских образовательных организаций;

Эффективность реализации разработанной нами Модели была подтверждена опытным путем и указала на эффективность совершенствования педагогического обеспечения интеграции дошкольного и дополнительного образования дошкольников.

\section{ЛИТЕРАТУРА}

1. Ерешкина Л.В, Кошкина И.В. Проблема интеграции дошкольного и дополнительного образования в условиях городской образовательной среды // Современное педагогическое образование. 2020. №10. С. 93-99. С. 99.

2. Кошкина И.В. Условия формирования конфликтологической компетентности у педагогов дошкольной образовательной организации // Изв. Сарат. ун-та Нов. сер. Сер. Акмеология образования. Психология развития. 2017. №1. С. 10-14.

3. Ерешкина Л.В, Кошкина И.В. Взаимодействие основного и дополнительного образования в Д00, способы интеграции // Теория и практика современной науки. 2017. №12(20). С. 842-849

4. Вахрамеева 0.А. Значение мотивационной сферы в адаптации дошкольника к обучению в условиях массовой школы // Вестник Шадринского государственного педагогического университета. 2018. №2 (38). URL: https://cyberleninka.ru/article/n/znachenie-motivatsionnoy-sfery-v-adaptatsii-doshkolnika-kobucheniyu-v-usloviyah-massovoy-shkoly (дата обращения: 09.03.2021).

5. Волкова Т.Н., Казаков И.С. Исследование готовности старших дошкольников к школьному обучению // Молодой ученый. - 2016. - № 9.3. - С. 5-6.

6. Тихомирова Е.И. Исследование технологий субъектной самореализации личности // Ярославский педагогический вестник. 2015. № 2. Т. 2. С. 91-96.

7. Байбородова Л.В. Проектирование индивидуальной образовательной деятельности ребенка. Психолого-педагогические проблемы развития современного школьника: колл. монография / отв. ред. А.Ю. Нагорнова. Ульяновск : Изд-во «Зебра», 2016. С. 44-58.

8. Байбородова Л.В. Использование субъектно-ориентированной технологии воспитания в проектной деятельности // Воспитание школьников. 2017. № 4. C. 3-10.

9. Аксененко, С.В. Организация работы студий и творческих мастерских в дошкольном образовательном учреждении / С.В. Аксененко, 0.И. Русанова, Л.В. Рязанцева. — Текст: непосредственный // Вопросы дошкольной педагогики. — 2020. — № 10 (37). — C. 15-17. — URL: https://moluch.ru/th/1/ archive/183/5708/ (дата обращения: 11.03.2021).

10. Федина Н.В., Бурмыкина И.В., Звезда Л.М. и др. Дистанционные образовательные технологии в системе дошкольного образования: научные подходы и перспективы развития // Проблемы современного образования. 2017. №5. URL: https://cyberleninka.ru/article/n/distantsionnye-obrazovatelnyetehnolologii-v-sisteme-doshkolnogo-obrazovaniya-nauchnye-podhody-i-perspektivy-razvitiya (дата обращения 09.03.2021).

(с) Ерешкина Лариса Владимировна (larisa-700@mail.ru).

Журнал «Современная наука: актуальные проблемы теории и практики» 